\title{
Cities should respond to the biodiversity extinction crisis
}

\author{
Cathy Oke $\mathbb{C}^{1,2,3 凶}$, Sarah A. Bekessy ${ }^{4}$, Niki Frantzeskaki ${ }^{5}$, Judy Bush $\mathbb{1}^{6}$, James A. Fitzsimons $\mathbb{\mathbb { D }}^{7,8}$, Georgia E. Garrard ${ }^{4}$, Maree Grenfell ${ }^{9}$, \\ Lee Harrison ${ }^{3}$, Martin Hartigan ${ }^{7,9}$, David Callow ${ }^{3}$, Bernie Cotter ${ }^{2}$ and Steve Gawler ${ }^{2}$
}

Cities globally are greening their urban fabric, but to contribute positively to the biodiversity extinction crisis, local governments must explicitly target actions for biodiversity. We apply the Intergovernmental Science-Policy Platform on Biodiversity and Ecosystem Services (IPBES) framework - nature for nature, society and culture - to elevate local governments' efforts in the lead up to the 2021 UN Biodiversity Conference. The UN's Vision of Living in Harmony with Nature can only be realised if cities are recognised and resourced for their roles in biodiversity protection - for nature, for society and for culture.

npj Urban Sustainability (2021)1:11; https://doi.org/10.1038/s42949-020-00010-w

\section{INTRODUCTION}

Following the release of the Global Assessment Report on Biodiversity by the Intergovernmental Science-Policy Platform on Biodiversity and Ecosystem Services (IPBES) ${ }^{1}$, awareness of the biodiversity extinction crisis has heightened, catalysing calls for cities and nations to respond. Mass global protests, including youth climate strikes and Extinction Rebellion, and crises such as the Australian bushfires are increasingly engaging local and subnational governments with these issues. In responses to date, more than 1700 jurisdictions from around the world have declared a climate emergency, many linking their actions on climate change to biodiversity.

The $15^{\text {th }}$ meeting of the Conference of the Parties to the Convention on Biological Diversity (CBD COP 15), with a theme of 'Ecological Civilization: Building a Shared Future for All Life on Earth', will be held in Kunming, China in 2021. At this gathering, the Post-2020 Global Biodiversity Framework to safeguard nature and its contributions to human well-being will be determined by national governments. This is a vital opportunity to address the extinction crisis alongside the climate emergency, as well as embedding cities' previous and ongoing roles in these global efforts for nature restoration. 'Nature' is understood here as biodiversity (species, habitats and ecosystems) that is native to the region, consistent with the CBD and IPBES. Although non-native species, which are common in cities, can provide important ecosystem services and other benefits, native species (including threatened species) are typically more diverse and abundant in native habitats ${ }^{2}$.

Nature-based solutions are systemic solutions that employ nature's ability to regulate, restore, and regenerate resources. There is increasing evidence of the efficacy of nature-based solutions for addressing complex urban challenges such as urbanisation and climate change ${ }^{3}$. Accordingly, cities are increasingly investing in a broad array of nature-based solutions as adaptation and mitigation measures. Recently, the city of Rotterdam announced an investment of $€ 233$ million in a Green Metamorphosis - a city-wide regeneration program for public squares and open spaces towards a diverse network of naturebased solutions that will replace impermeable surfaces, contributing to biodiversity and civic amenity ${ }^{4}$. The CitiesWithNature platform (https://citieswithnature.org/) hosts cities with dedicated strategies on biodiversity and nature-based solutions to share knowledge and create a global community of pioneering local and subnational governments. For example, the cities of Montreal and Melbourne have incorporated biodiversity actions into strategic plans. The city of Edmonton has an extensive network of biodiversity corridors across the city and its periphery. Yet, while these mounting actions show a shift towards biodiversity action at the local scale, for cities to effectively respond to the extinction crisis, nature-based solutions need to explicitly address and deliver on biodiversity conservation.

Our perspective paper aims to provide strategic direction for addressing the extinction crisis in cities to urban planners, designers, policy makers and researchers. We utilise the IPBES conceptual framework ${ }^{5}$ that positions three dimensions of nature - 'nature for nature', 'nature for society' and 'nature for culture' - to propose a suite of opportunities for effective nature-based solutions to benefit biodiversity. In the following sections, we discuss how urban nature addresses these dimensions and identify priorities for action. We argue that cities' roles in responding to the extinction crisis should be explicitly acknowledged and coordinated, and targeted actions identified to amplify their effectiveness locally and globally. We propose solutions that could form the foundations for a bolder progressive agenda for discussion at the CBD COP 15.

\section{NATURE FOR NATURE}

The IPBES framework recognises nature's intrinsic value, 'nature for nature' ${ }^{\prime 5}$. Cities around the world host numerous species and ecological communities ${ }^{6}$, and can be hotspots for threatened species $^{7}$, yet urbanisation processes continue to threaten biodiversity. Cities are particularly important for some species as they can provide stable, year-round resources due to plant selection and watering regimes ${ }^{8}$. Research is identifying important links between people's everyday experiences of nature, their connectedness with nature and their commitment to pro-biodiversity practices ${ }^{9}$. Priorities for nature for nature actions should include:

\footnotetext{
${ }^{1}$ Connected Cities Lab, The University of Melbourne, Melbourne, VIC 3010, Australia. ${ }^{2}$ ICLEI - Local Governments for Sustainability, Oceania, L8 225 Bourke Street, Melbourne, Victoria 3000, Australia. ${ }^{3}$ City of Melbourne, GPO Box 1603, Melbourne 3001, Australia. ${ }^{4}$ ICON Science, School of Global, Urban and Social Studies, RMIT University, GPO Box 2476, Melbourne 3001 for ICON, Australia. ${ }^{5}$ Centre for Urban Transitions, Swinburne University of Technology, Hawthorn, Australia. ${ }^{6}$ Faculty of Architecture, Building and Planning, The University of Melbourne, Melbourne, VIC 3010, Australia. ${ }^{7}$ The Nature Conservancy, Suite 2-01, 60 Leicester Street, Carlton, VIC 3053, Australia. ${ }^{8}$ School of Life and Environmental Sciences, Deakin University, Melbourne, Australia. ${ }^{9}$ Resilient Melbourne, GPO Box 1603, Melbourne 3001, Australia. ${ }^{凶}$ email: cathy.oke@unimelb.edu.au
} 
Recognise and implement city-level obligations and responsibilities to biodiversity

With 193 Parties, the CBD has near-universal participation among countries. Cities, and the governments that govern them, have important roles in ensuring obligations of the Convention are met within the footprint of urban areas, as recognised at COP10: Plan of Action on Subnational Governments, Cities and Other Local Authorities for Biodiversity (UNEP/CBD/COP/DEC/10/22). It is critical that the $\mathrm{CBD}$ continues to engage with city-focused efforts such as the Singapore Cities Biodiversity Index and the Edinburgh Process for Subnational and Local Governments on the development of the Post 2020 global biodiversity framework ${ }^{10}$. It is important that CBD and cities explicitly acknowledge these roles and responsibilities when valuing nature and incorporating 'nature-for-nature' principles in strategies, planning and implementation.

Guide biodiversity objectives in urban planning using systematic approaches

A major obstacle to achieving 'nature for nature' is a lack of systematic approaches to setting objectives, identifying actions and implementing plans that contribute to biodiversity. Biodiversity conservation is often an ad hoc co-benefit of other actions, rather than an explicit strategic priority that is systematically planned across the whole city. With a few notable exceptions, e.g. Montreal and Melbourne, most cities have only recently begun incorporating biodiversity into strategic planning and urban agendas $^{11}$. We propose that systematic approaches are needed to complement and re-formulate decision-making tools. Designdriven approaches for enriching nature-for-nature functions and spaces in cities, such as biodiversity-sensitive urban design ${ }^{12}$, need to be scaled up.

Promote novel ecosystems as climate solutions in cities

Cities can be hostile environments for native vegetation because urban environments are typically highly modified. Climate change amplifies many of these effects, and adds to the planning complexity, since biodiversity conservation objectives may be undermined by, or conflict with, objectives such as cooling and shading $^{13}$. We propose a shift from relying on historic models for restoring ecosystems, towards applying nature conservation goals to novel ecosystems that are adaptive to climate change ${ }^{14}$. For this, we need to create mechanisms and communicate ecological designs that adjust and reconceptualise urban nature for evolving climates. An example from Melbourne Australia is the addition of native mistletoes (that provide habitat for insects and birds) to exotic trees that provide shading and cooling ${ }^{15}$.

\section{Confront and address human-nature conflicts in cities}

The increased contact of people with nature in cities can pose new challenges for urban administrators. In some situations, urban biodiversity is viewed as unpleasant, dangerous or destructive ${ }^{16}$. We propose an approach to human-biodiversity conflicts that combines design and communication. Careful design to reduce potential conflict should examine services and disservices, and catalogue effective solutions to conflicts, some of which may also be tied to patterns of inequality ${ }^{17}$. An open dialogue and learningfocused approach about the benefits of nature, which also addresses conflicts and fears of nature, may increase nature literacy, decrease injustice in cities and manage conflicts.

\section{NATURE FOR SOCIETY}

'Nature for society' represents the utilitarian values of nature ${ }^{5}$. Nature-based solutions including green roofs, wetlands, daylighted water bodies, sustainable urban drainage systems and more, improve climate resilience, air and water quality and reduce flooding ${ }^{3}$. In embedding nature-based solutions in programs for climate resilience, a wide range of other sustainability challenges need to be addressed, including alleviation of poverty, hunger, provision of health, education, clean water, economic growth, sustainable cities and climate action (Sustainable Development Goals 1,2,3,4,6,8,11,13). Direct economic benefits flow from employment opportunities and green jobs, and indirect economic benefits are associated with energy savings and health care cost reductions. Many of the benefits of urban nature arise from interaction with structurally complex and biodiverse green space. For example, emerging evidence suggests that human health and well-being benefits may be enhanced by incorporating biodiverse nature in cities ${ }^{18,19}$. Structural and species diversity can improve the robustness of nature-based solutions in the face of threats from extreme weather, and disease and insect predation. In the face of accelerating urbanisation and climate challenges, naturebased solutions are increasingly important for resilient cities. In the current COVID-19 pandemic, urban parks and protected areas have become a lifeline for physical and mental health ${ }^{20}$. Priorities for nature for society actions should include:

\section{Creating resilient landscape systems}

For nature-based solutions to effectively deliver 'nature-for-society', they need to function as healthy and resilient ecosystems. We propose a systems approach to the design of nature-based solutions that requires their integration within the wider urban infrastructure systems ${ }^{21}$. This involves starting with the nature-based solutions as the systemic 'seeds' of solutions in the urban design processes, rather than as 'add-ons' if space and budget allows.

Mainstream resilience principles in the design and management of nature-based solutions

Urban resilience and climate change actions can be increased through the inclusion of nature-based solutions ${ }^{13}$. We propose that cities mainstream resilience principles as a guiding framework for designing and maintaining nature-based solutions as urban climate infrastructure. This requires strengthening the institutional role of urban resilience teams and the commitment to long-term targets for climate change.

Adopt experimentation and transdisciplinary research to strengthen and extend expertise

Testing and evaluating new designs of nature-based solutions across diverse urban typologies, together with their financing models and policy mechanisms, is critical. Experiments, including those that can be 'safe to fail'22, are vital to creating and trialling new approaches to nature-based solutions, and to adapting to changing urban conditions. Experimentation should be based on co-production across practitioner and academic communities to ensure relevance, rigour and replicability.

\section{NATURE FOR CULTURE}

'Nature for culture' acknowledges the importance of people's connections with nature, and the benefits of social cohesion, community connection, educational, and spiritual benefits ${ }^{5,6}$. Nature can provide the space in which urban communities reconnect with 'place'; establish a sense of belonging that enables social cohesion, health and well-being ${ }^{23}$. Different types of knowledge need to be brought together to co-produce socioecologically robust nature-based solutions. 'Nature for culture' acknowledges the importance of diverse knowledges, including First Nations and Traditional Owners ${ }^{24}$. Including diverse voices means that people and communities across different sectors, locations and demographics are invited and facilitated to contribute. This encourages the voices less heard, and less 
represented to ensure a just nature for culture. Priorities for nature for culture actions should include:

Co-produce knowledge with Indigenous peoples for bringing nature in cities

Indigenous knowledge differs from western scientific knowledge systems with different time horizons, axiology, complexity and conceptualisations. Prioritising and documenting Indigenous practices supports learning-focused urban experiments with Indigenous communities and may encourage increased stewardship and nature appreciation. Working in partnership with Traditional Owners and Indigenous knowledge systems requires cultural sensitivity and ability to respectfully generate actionable knowledge for planning cities with nature.

Use place-based nature to foster inclusivity in multicultural cities Cultural meanings and narratives of nature are part of strategic visions and policy objectives, as well as of education and communication programs. We propose culture to be the medium to bridge, connect, empower and represent diversity. This allows for nature to be a catalyst for inclusivity in multicultural cities. This can be realised by representing cultural meanings of nature in city festivals, ceremonies and educational programs for ecosystem literacy ${ }^{25}$.

Reconnect people with nature in cities through citizen science and engagement programs

Urban systems and lifestyles often lead to a sense of disconnection from nature ${ }^{9}$. This sense of nature disconnection may be reinforced by limited access to nearby nature in parks and gardens, and increasing time spent indoors, at work, or commuting to and from work. Citizen science can be a way to examine nature's place in cities, as can other engagement programs such as Wildlife Gardening $^{26}$ and place-based environmental education ${ }^{27}$.

\section{CONCLUSIONS}

Cities will play an increasingly significant role in global biodiversity conservation, as stewards of substantial biodiversity values and as sites for engaging the majority of the world's population in conservation issues. Cities can often be fragmented in jurisdiction and governance, but strategically planning for and restoring nature across the entire city extent can increase the benefits to nature and people in urban landscapes ${ }^{28}$. Provision of adequate funding and skills for both establishing and maintaining naturebased solutions is required. Ensuring cities have access to the necessary ecological and landscape skills is key (particularly as many urban systems are 'novel' ecosystems), but so too is the social licence to be courageous about targeted, concerted action.

City leaders must meet this urgency with prioritised and budgeted action, with the added challenge of addressing the complexity of nature itself. Solutions can be found in improving the design of nature-based solutions to address the multiple dimensions of nature for nature, society and culture', with stewardship of urban nature translating into citizens assuming the role of custodians for biodiversity.

The 15th Conference of the Parties to the Convention for Biological Diversity in 2021 presents a crucial opportunity — and imperative to strengthen and embed cities' roles in biodiversity conservation. We have identified priorities for action: to bolster nature for nature, to strengthen nature for society and to integrate nature for culture.

A transformational approach to urban nature futures, that responds to the extinction and climate change crises, should seek to maximise the achievement of all three dimensions. This requires an organisational shift to reduce professional and political obstacles and to align local objectives more closely with national and international goals. Documentation of cities' efforts in research and practice will be needed, noting that evidencebased local and international policy should be developed through universities, practitioners and Traditional Owners sharing knowledge across contexts, continents and disciplines. This creates opportunities for diverse urban nature-voices to co-create the case for biodiversity, and can be supported through the many existing local networks, as well as the global city networks and platforms, such as CitiesWithNature. At COP 15, CBD Parties should extend the Plan of Action on Subnational Governments, Cities and Other Local Authorities for Biodiversity from 2021 to 2030 and beyond, and the Global Biodiversity Summit of Local and Subnational Governments $^{28}$ would do well to be highlighted at COP 15. Cities have a responsibility to act urgently to achieve this vision, and should be recognised and resourced for the role they need to play in biodiversity protection - for nature, for society and for culture.

Received: 2 March 2020; Accepted: 11 August 2020; Published online: 23 February 2021

\section{REFERENCES}

1. IPBES. Global Assessment Report on Biodiversity and Ecosystem Services of the Intergovernmental Science-Policy Platform on Biodiversity and Ecosystem Services (eds. Brondizio, E.S., Settele, j., Díaz, s. \& Ngo, H.T.) (IPBES Secretariat, Bonn, Germany, 2019).

2. Champness, B. S., Palmer, G. C. \& Fitzsimons, J. A. Bringing the city to the country: relationships between streetscape vegetation type and bird assemblages in a major regional centre. J. Urban Ecol. 5, juz018 (2019).

3. Frantzeskaki, N. et al. Nature-based solutions for urban climate change adaptation: linking the science, policy and practice communities for evidence based decision-making. BioScience 69, 455-566 (2019).

4. Willeme, A. Rotterdam drops $€ 233$ million on green spaces-and they look INCREDIBLE. DutchReview. https://dutchreview.com/cities/rotterdam-drops-233million-on-green-spaces-and-they-look-incredible/ (18 June 2020).

5. Díaz, S. et al. The IPBES Conceptual Framework - connecting nature and people. Curr. Opin. Environ. Sustain. 14, 1-16 (2015).

6. Elmqvist, T. et al. (eds). Urbanization, Biodiversity and Ecosystem Services: Challenges and Opportunities. A Global Assessment (Springer, Dordrecht, 2013).

7. Ives, C. et al. Cities are hotspots for threatened species. Glob. Ecol. Biogeograph. 25, 117-126 (2016).

8. Parris, K. M. \& Hazell, D. L. Biotic effects of climate change in urban environments: the case of the grey-headed flying-fox (Pteropus poliocephalus) in Melbourne, Australia. Biol. Conserv. 124, 267-276 (2005).

9. Prévot, A. C., Cheval, H., Raymond, R. \& Cosquer, A. Routine experiences of nature in cities can increase personal commitment toward biodiversity conservation. Biol. Conserv. 226, 1-8 (2018).

10. ICLEI CBC. Edinburgh Process for Subnational and Local Governments on the Development of the Post 2020 Global Biodiversity Framework (ICLEl, 2020). https:// cbc.iclei.org/edinburgh-process-for-subnational-and-local-governments-on-thedevelopment-of-the-post-2020-global-biodiversity-framework/.

11. Nilon, $C$. et al. Planning for the future of urban biodiversity: a global review of city-scale initiatives. BioScience 67, 332-342 (2017).

12. Garrard, G. E., Williams, N. S. G., Mata, L., Thomas, J. \& Bekessy, S. A. Biodiversity sensitive urban design. Conserv. Lett. 11, e12411 (2018).

13. Bush, J. \& Doyon, A. Building urban resilience with nature-based solutions: how can urban planning contribute? Cities 95, 102483 (2019).

14. Prober, S. M., Doerr, V. A. J., Broadhurst, L. M., Williams, K. J. \& Dickson, F. Shifting the conservation paradigm: a synthesis of options for renovating nature under climate change. Ecol. Monog. 89, e01333 (2019).

15. Canaway, J. Unveiling the misunderstood magical mistletoes of Australia. ABC Life. https://www.abc.net.au/life/the-misunderstood-magical-mistletoes-of-australia/ 11505510 (20 December 2019).

16. Burgin, S. What about biodiversity? Redefining urban sustainable management to incorporate endemic fauna with particular reference to Australia. Urban Ecosys. 19, 669-678 (2016).

17. Rigolon, A. A complex landscape of inequity in access to urban parks: a literature review. Landsc. Urban Plann. 153, 160-169 (2016).

18. Fuller, R. A. et al. Psychological benefits of greenspace increase with biodiversity. Biol. Lett. 3, 390-394 (2007).

19. Sugiyama, T., Carver, A., Koohsari, M. J. \& Veitch, J. Advantages of public green spaces in enhancing population health. Landsc. Urban Plann. 178, 12-17 (2018). 
20. Hockings, M. et al. COVID-19 and protected and conserved areas. Parks 26.1, 7-24 (2020).

21. Frantzeskaki, N. Seven lessons for planning nature-based solutions in cities. Environ.Sci. Pol. 93, 101-111 (2019).

22. Ahern, J. From fail-safe to safe-to-fail: sustainability and resilience in the new urban world. Landsc. Urban Plann. 100, 341-343 (2011).

23. Kabisch, N., van den Bosch, M. \& Lafortezza, R. The health benefits of naturebased solutions to urbanization challenges for children and the elderly-a systematic review. Environ. Res. 159, 362-373 (2017).

24. Tengö, M. et al. Weaving knowledge systems in IPBES, CBD and beyondlessons learned for sustainability. Curr. Opin. Environ. Sustain. 26-27, 17-25 (2017).

25. Davies, C. \& Lafortezza, R. Transitional path to the adoption of nature-based solutions. Land Use Pol. 80, 406-409 (2019).

26. Mumaw, L. M. \& Bekessy, S. A. Wildlife gardening for collaborative public-private biodiversity conservation. Austral. J. Environ. Manage. 24, 242-246 (2017).

27. Eilam, E. \& Garrard, G. E. Perception of space among children studying their local grasslands: examining attitudes and behavioural intentions. Sustainability 9, 1660 (2017).

28. ICLEl. 6th Global Biodiversity Summit of Local and Subnational Governments. Event Report (2018) https://cbc.iclei.org/wp-content/uploads/2019/10/Egypt-SummitEVENT-REPORT-FINAL-digital_compressed.pdf.

\section{ACKNOWLEDGEMENTS}

S.A.B. and G.G. are supported by the Australian Government's National Environmental Science Program through the Clean Air and Urban Landscapes and Threatened Species Recovery Hubs and ARC Linkage Grant LP160100324. S.A.B. is also supported by the European Union's H2020 project No 730426 (URBAN GreenUP). We acknowledge Professor Thomas Elmqvist as the keynote speaker at the Melbourne Town Hall workshop at which this paper was developed.

\section{AUTHOR CONTRIBUTIONS}

All authors contributed equally to the development of concept for this paper and the first draft of the manuscript during a two-day writing workshop; and all reviewed the submitted and re-submitted manuscript. C.O., S.A.B., N.F., J.B., J.A.F., G.E.G., M.G., L.H. and M.H. all contributed equally to the writing and editing process that produced the originally submitted manuscript, and review and edits for revised and final manuscripts.

\section{COMPETING INTERESTS}

The authors declare no competing interests. While not considered a conflict, we note that C.O., B.C. and S.G. are affiliated with ICLEI - Local Governments for Sustainability and J.A.F and M.H. are affiliated with The Nature Conservancy, two of the founding organisations of the CitiesWithNature platform mentioned in the manuscript.

\section{ADDITIONAL INFORMATION}

Correspondence and requests for materials should be addressed to C.O.

Reprints and permission information is available at http://www.nature.com/ reprints

Publisher's note Springer Nature remains neutral with regard to jurisdictional claims in published maps and institutional affiliations.

Open Access This article is licensed under a Creative Commons C. Attribution 4.0 International License, which permits use, sharing, adaptation, distribution and reproduction in any medium or format, as long as you give appropriate credit to the original author(s) and the source, provide a link to the Creative Commons license, and indicate if changes were made. The images or other third party material in this article are included in the article's Creative Commons license, unless indicated otherwise in a credit line to the material. If material is not included in the article's Creative Commons license and your intended use is not permitted by statutory regulation or exceeds the permitted use, you will need to obtain permission directly from the copyright holder. To view a copy of this license, visit http://creativecommons. org/licenses/by/4.0/.

(c) The Author(s) 2021 